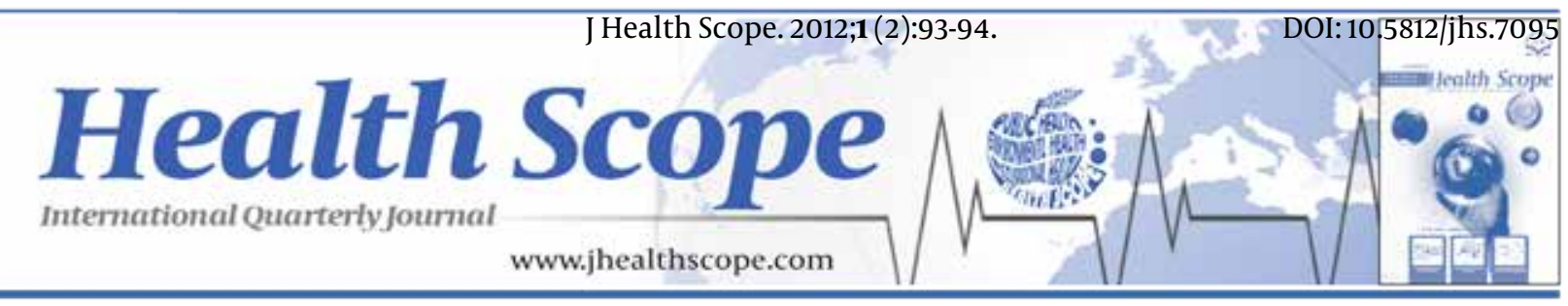

\title{
Are Food Supplements and Phytotherapeutics Potential Pharmacolog- ical Alternatives to Conventional Medications?
}

\author{
Maurizio Coppola ${ }^{1^{*}}$ \\ ${ }^{1}$ Department of Addiction, Alba (CN), Italy
}

\begin{tabular}{l}
\hline A R T I C L E I N F O \\
\hline Article type: \\
Letter to Editor \\
\hline Article history: \\
Received: 19 Jun 2012 \\
Revised: 23 Jun 2012 \\
Accepted:11 Jul 2012 \\
\hline Keywords: \\
Supplement, Food \\
Pharmacological \\
Medication
\end{tabular}

\section{Dear Editor,}

Congratulations for your new and important editorial initiative. I read with great interest the articles published within the first issue of the Journal, in particular the paper entitled: "The Effect of Education on Nutrition Behavioral Intention and Self-Efficacy in Women". In the last years, the use of food supplements and nutraceuticals is continually on the rise. Although they are often used improperly, clinical data suggest that many of these substances along with a correct physical activity produce a significant therapeutic action (in combination with traditional treatments) in several acute and chronic diseases including diabetes, metabolic disorders, obesity, hypertension, food allergies, central nervous system and psychiatric disorders. Since some years, several studies have shown that some food supplements such as omega 3 and vitamins of $B$ group as well as physical activity can play an important role as adjuvants for treating mood disorders $(1,2)$. Thus it is not surprising that both ketamine

\author{
Please cite this paper as: \\ Coppola M. Are Food Supplements and Phytotherapeutics Po- \\ tential Pharmacological Alternatives to Conventional Medica- \\ tions? Health Scope. 2012; 1 (2): 93-4.
}

and the amino acid leucine act at the mammalian target of rapamycin (mTOR) pathway, a serine/ threonine protein kinase that plays a key role in the NMDA receptor antagonists induced rapid acting antidepressant effects $(3,4)$. We cannot deny that an increasing professional specialization of doctors is in conflict with a holistic therapeutic approach to many diseases. In the future will be interesting to investigate the effect of food supplements such as omega 3, vitamin B12, folic acid and pomegranate administered during pregnancy in cases with high vulnerability for metabolic, inflammatory, neurological and psychiatric diseases. Furthermore, a holistic view of medicine includes the phytotherapy, and in this regard, the study about anticonvulsant effect of hydro-alcoholic extract of Melissa Officinalis (original article entitled:" Comparing Anticonvulsive Effect of Melissa Officinalis` Hydro-Alcoholic Extract and Phenytoin in Rat") is very interesting. Some botanicals and herbs such as valerian, pipsissiwa, skullcap, betony and other have shown antiepileptic properties (5). Despite the widespread use of herb-

\footnotetext{
* Corresponding author: Maurizio Coppola, Department of Addiction, ASL CN2, Viale Coppino 46, 12051, Alba (CN), Italy. Tel: +39-173316210, Fax: +39-173420344, E-mail: coppolamail@alice.it
} 
al therapies by patients with epilepsy and the anecdotal reports of effectiveness, there is a paucity of controlled evidence to support their use. Further studies are needed to investigate the clinical efficacy and safety of these vegetable products with scientific methods. Self-management of herbal products and food supplements as well as the information from invalud sources are dangerous, but the unconventional pharmacological treatments must be considered as a real therapeutic option in the modern medicine. In addition, these therapies may potentially yield new treatment options for patients affected from various diseases, and may also represent inexpensive and culturally acceptable treatments for millions of patients worldwide. However, considering the potential risks and benefits of these pharmacological alternatives, the effectiveness should be only evaluated using the evidence based medicine criteria. The medical community must abandon its prejudices judging the data objectively:" The absence of proof is not proof of absence".

\section{Authors' Contribution}

This study has been done completely by author.

\section{Financial Disclosure}

None declared.

\section{References}

1. Sarris J, Mischoulon D, Schweitzer I. Adjunctive nutraceuticals with standard pharmacotherapies in bipolar disorder: a systematic review of clinical trials. Bipolar Disord. 2011;13 (5-6):454-65.

2. Ng F, Dodd S, Berk M. The effects of physical activity in the acute treatment of bipolar disorder: a pilot study. J Affect Disord. 2007;101 (1-3):259-62.

3. Li N, Lee B, Liu RJ, Banasr M, Dwyer JM, Iwata M, et al. mTOR-dependent synapse formation underlies the rapid antidepressant effects of NMDA antagonists. Science. 2010;329 (5994):959-64.

4. Li F, Yin Y, Tan B, Kong X, Wu G. Leucine nutrition in animals and humans: mTOR signaling and beyond. Amino Acids. 2011;41 (5):1185-93.

5. Pearl PL, Drillings IM, Conry JA. Herbs in epilepsy: evidence for efficacy, toxicity, and interactions. Semin Pediatr Neurol.2011;18 (3):203-8. 